\title{
ON A POSSIBLE INFLUENCE OF MAGNETIC FIELDS ON THE STRUCTURE OF A DISK FORMED DURING ACCRETION OF PLASMA IN BINARY SYSTEMS
}

\author{
L. A. PUSTILNIK and V. F. SHVARTSMAN \\ Special Astrophysical Observatory, U.S.S.R. Academy of Sciences, \\ St. Zelenchukskaya, Stavropolskij Kraj 357140, U.S.S.R.
}

\begin{abstract}
During accretion of plasma in binary systems containing compact objects magnetic fields are most likely to become arranged quickly, grow and fully determine the disk structure. The disk divides into separate dense clots, and a corona appears over the equatorial plane of the system. In the corona magnetic lines of force reconnect and beams of relativistic particles are generated.
\end{abstract}

\section{Reference}

Pustilnik, L. A. and Shvartsman, V. F.: 1973, Commun. SAO U.S.S.R. AS, in press. 